\title{
Computer-Supported Collaborative Learning in STEM Domains: Towards a Meta-synthesis
}

\author{
Cindy E. Hmelo-Silver \\ Indiana University \\ chmelosi@indiana.edu
}

\author{
Heisawn Jeong \\ Hallym University \\ heis@hallym.ac.kr
}

\author{
Kylie Hartley \\ Indiana University \\ hartley2@indiana.edu
}

\author{
Roosevelt T. Faulkner \\ Indiana University \\ rtfaulkn@indiana.edu
}

\begin{abstract}
Computer-Supported Collaborative Learning (CSCL) research has become pervasive in STEM education over the last several decades. The research presented here is part of an ongoing project to construct a meta-synthesis of CSCL findings in STEM domains. After a systematic search of the literature and article coding, cluster analysis results provided a frame for sampling from this literature in order to examine effects of CSCL. This preliminary metasynthesis addresses the three key pillars of CSCL: the nature of collaboration, the technologies that are employed, and the pedagogical designs.
\end{abstract}

\section{Introduction}

Computer-Supported Collaborative Learning (CSCL) research has become pervasive in STEM education over the last several decades [31]. CSCL makes extensive use of digital technologies and social media but also mirrors epistemic shifts in education, such that many contemporary theorists characterize learning as that which is social and collective rather than individual. The changing pedagogies and evolving technologies have merged to create many new CSCL opportunities in STEM classrooms [22]. A comprehensive review of the effects of CSCL research thus a synthesis is timely given the substantial investment in technology. The research here is part of an ongoing effort to construct a meta-synthesis of CSCL literature in STEM domains [14]. We conduct this synthesis with respect to CSCL goals of helping learners engage in collaborative meaning making that focuses on the construction of flexible knowledge [22, 31]. In describing the goal of research in CSCL, Miyake argued that to understand how CSCL research was fulfilling its goals, research on learning is needed that "takes collaboration seriously, and implements and evaluates technological support to materialize effective learning designs" [22, p. 248]. This preliminary synthesis addresses the three key pillars of CSCL: the nature of collaboration, the technologies that are employed, and the pedagogical designs. By looking at different combinations of design elements of CSCL, we can get closer to answering the question about the effects of different CSCL designs on learning for different learning contexts.

A preliminary meta-analysis of CSCL found an overall moderate effect of CSCL on learning outcomes, but also that the patterns of effects differ for primary and secondary students as compared to students in higher education and other adults [13]. In addition, these levels interact with types of collaboration, pedagogy and technologies (see Table 1). But just looking at overall effects in meta-analysis does not get at the nuance that is part of the complexity of CSCL. For that, we need to look beyond meta-analysis, which focuses only on quantitative studies and synthesize across different methodological accounts of CSCL. The goal here is to create a meta-synthesis of the CSCL research literature in STEM education to better understand under what circumstances CSCL is more or less effective while integrating research findings across qualitative and quantitative studies [1]. This allows researchers to synthesize empirical studies by first classifying them into several categories, using either inductive or deductive methods to develop codes. In this research, these codes were useful in classifying many study characteristics [14], but identifying outcome patterns requires a subtler approach. A latent cluster analysis (LCA) was used to characterize the results of systematic coding of the CSCL literature in STEM domains, which were then used to guide the sampling of papers for the meta-synthesis.

\section{Methods}

We conducted a systematic review of CSCL literature in STEM domains from seven key journals and two databases, ERIC and Web of Science. The seven journals were regarded by experts to be leaders in publishing CSCL research [14]. We screened 1,095 articles published between 2011-2014 to ensure each 
paper met the following criteria: (a) STEM education, (b) empirical research, and (c) use of technology to support collaborative learning. The 295 papers that met our criteria were further coded based on the following dimensions: (a) education level (b) collaboration, (c) pedagogy, and (d) technology, described in Table 1. Note that these pedagogy and technology code categories were aggregated from lower level codes.

\subsection{Latent class analysis (LCA) and meta- synthesis}

To identify and characterize groups of similar cases, a Latent Class Analysis (LCA) was performed.
LCA is a technique that processes multivariate categorical data by modeling the cross-classification table of the observed variables by an unobserved unordered categorical variable. The outcome is then a model that explicitly provides group probabilities for each observation into a latent class. Selection of the best fitting model proceeds by making use of parsimony and goodness-of-fit statistics.

A separate meta-analysis in progress suggests educational levels moderate CSCL effects [15] therefore, in this proposal we are only sampling from the 199 papers coded for the education levels, K-12 or higher education.

Table 1. Coding dimensions

\begin{tabular}{|c|c|c|}
\hline Dimensions & Categories & Descriptions \\
\hline \multirow[t]{4}{*}{ Collaboration } & Mediated & Face-to-face collaboration with technology (e.g., joint work on simulation) \\
\hline & Synchronous & $\begin{array}{l}\text { Collaborative communication occurring at same time (e.g., simultaneous } \\
\text { videoconference) }\end{array}$ \\
\hline & Asynchronous & $\begin{array}{l}\text { Collaborative communication occurring at different times (e.g., threaded } \\
\text { discussion occurring over a week) }\end{array}$ \\
\hline & Various & Two or more of the above collaboration types \\
\hline \multirow[t]{5}{*}{ Pedagogy } & Discussions & $\begin{array}{l}\text { Students given broad directions to discuss topics and/or engage in } \\
\text { argumentation. }\end{array}$ \\
\hline & $\begin{array}{l}\text { Inquiry } \\
\text { Exploration }\end{array}$ & $\begin{array}{l}\text { Students engage in structured exploration of real world problems, often with } \\
\text { driving question and/or in defined learning cycles (e.g., problem-based } \\
\text { learning, inquiry learning) }\end{array}$ \\
\hline & Teacher directed & $\begin{array}{l}\text { Instruction is teacher-centered and focus on delivering and reinforcing content } \\
\text { (e.g., traditional distance learning) }\end{array}$ \\
\hline & Other & Other pedagogies not listed (e.g. Jigsaw) \\
\hline & Various & Two or more of the above pedagogies \\
\hline \multirow[t]{8}{*}{ Technology } & $\begin{array}{l}\text { Asynchronous } \\
\text { communication }\end{array}$ & $\begin{array}{l}\text { Enable asynchronous collaboration (e.g., email, discussion board, Knowledge } \\
\text { Forum) }\end{array}$ \\
\hline & $\begin{array}{l}\text { Synchronous } \\
\text { communication }\end{array}$ & Enable synchronous collaboration (e.g., chat, video conferencing) \\
\hline & Dynamic tools & $\begin{array}{l}\text { Enable interactive manipulations based on user actions (e.g., simulations, } \\
\text { games, immersive technology) }\end{array}$ \\
\hline & $\begin{array}{l}\text { Groups and } \\
\text { communities }\end{array}$ & Enable collaboration with increased social presence (e.g. Social media) \\
\hline & $\begin{array}{l}\text { Integrated } \\
\text { Environments }\end{array}$ & $\begin{array}{l}\text { Enable an integrated use of multiple technologies (e.g. Learning Management } \\
\text { Systems) }\end{array}$ \\
\hline & $\begin{array}{l}\text { Sharing and co- } \\
\text { construction }\end{array}$ & Enable students to openly share, create, and modify information (e.g., wikis) \\
\hline & Other & Other technologies not listed (e.g. game-authoring tools) \\
\hline & Various & Two or more of the above technologies \\
\hline
\end{tabular}


For the initial meta-synthesis effort, presented here, we selected 8 articles from each cluster, attempting to distribute these evenly across quantitative and qualitative research. These papers are referenced in their relevant cluster findings. For the meta-synthesis, we began by identifying outcomes and then looked for conditions or variables that moderated findings of the clusters.

While being aware of educational levels, we compared outcomes across technology, collaboration, and pedagogy. Once we came up with a synthesis for each cluster, we then looked for themes and patterns across the clusters.

\section{Findings}

The best model was selected using the AIC and Deviance criteria, the lower its value the better the fit to the data. Thus, the best model includes four clusters, $\mathrm{k}=4$ with $\mathrm{AIC}=2654.70$. Clusters were descriptively named based on dominant pedagogy, technology, and/ or collaboration type. When there was no dominant pedagogy or technology, mixed was used as a descriptor. Shown in Table 2, descriptive results show $34 \%$ of the papers belong to "Mixed Asynchronous" Cluster 1, 41\%, to "Mediated Inquiry" Cluster 2, 13\% to "Asynchronous Discussion" Cluster 3, and 12\% to "Mixed Synchronous" Cluster 4. As Table 2 shows, each cluster is characterized with different covariation of technology, pedagogy, and collaboration.

To help interpret these clusters, we also present descriptive statistics of the unaggregated categories for technology and pedagogy in Tables 3 and 4 . Note that the totals for Tables 3 and 4 are different from Table 2 as our initial coding included multiple technologies and/or pedagogies for individual papers, whereas such papers were in the "Various" category for the LCA so as to only be counted once.

For example, Cluster 2 demonstrates that studies investigating face-to-face collaboration were likely to use dynamic technologies such as games and simulations with pedagogies that were student-centered and focused on developing students' knowledge construction and skills through active inquiry and exploration. Cluster 4 indicates that synchronous CSCL is likely to use synchronous communication tools as well as dynamic representational tool with mixed pedagogical approaches. Many CSCL studies use asynchronous collaboration, and there are two distinct subgroups of studies depending on the used technology and pedagogy. Cluster 3 indicates that asynchronous technologies such as threaded discussions were, not surprisingly, preferred tools when using discussion pedagogy. Cluster 1, however, demonstrates an alternative arrangement to support asynchronous collaboration that rely on in integrated (e.g., learning management systems) or collaborative environments (e.g. wikis) with a range of pedagogies including discussion. Based on these cluster characteristics, we synthesized outcomes across a small sample from each cluster and then across clusters.

\subsection{Cluster 1: Mixed asynchronous}

The Mixed Asynchronous Cluster (Cluster 1), represents papers emphasizing asynchronous collaboration with discussion pedagogies using integrated CSCL environments and a variety of other tools such as online social network [34] mobile learning platforms [17], a social question and answer service [3], wiki technology [26], online discussion forums [15, 24, 35], and peer assessment tools [17, 24] The technologies used in this cluster are further broken down in Table 4. As Table 3 shows, the papers in this cluster used a range of distance and blended approaches to learning along with discussions, knowledge building, problem and project-based pedagogies.

Quantitative results showed that students using an online social network environment had higher degrees of interaction with peers and better grades than students using a traditional online platform [34]. Furthermore, survey results showed that students were generally satisfied with social CSCL tools (e.g., a mobile platform for online discussion, social question and answer service [3, 17]. Qualitative results focused on the content within the knowledge exchange, which highlighted speech acts and behavior patterns. In addition to social technologies, explicit guidance from the teacher or within the system resulted in salient occurrences of co-construction of knowledge and meaning making and exploratory talk, in which students made an effort in intersubjective orientation with their peers [3, 24, 25]. Noting frequency of collaboration and behavior patterns seemed to be the main focus in these studies. Technologies that fostered a sense of community and facilitated interactions resulted in high frequency of collaboration, learning achievement, and satisfaction [3, 17, 24, 25, 35] than technologies that did not $[15,35]$.

Social presence and explicit guidance have a major impact on student engagement on collaborative tasks within the system. However, when these aspects were not salient (i.e. social presence was not perceived, or teachers did not clearly state their expectations or encouraged desired interactions), interactions were somewhat disappointing. Joubert and Wishart [25] reported that although teachers encouraged classroom and online discussions, the majority of posts were not 
substantive. Students' postings were short and indicated they did not read previous posts before contributing their knowledge statements, thus creating threads that lacked cohesion. Furthermore, contributions in online discussion forums tended to be sporadic, interrupted, incomplete, and at times incomprehensible [35].

\subsection{Cluster 2: Mediated inquiry}

Cluster 2, the "Mediated Inquiry" Cluster, represents papers emphasizing face-to-face mediated collaboration, with inquiry and exploration pedagogies that use dynamic technological tools such as simulations and immersive technologies $[5,11,20,27$, $38,39]$ or games [16, 32]. Table 3 shows the clear dominance of the different inquiry and exploration pedagogies in this cluster. The lack of communications technology is a hallmark of this group of papers as much of it involved face-to-face collaboration (118 of 122 papers). The sampled papers demonstrate a range of positive outcomes reflected across quantitative and qualitative methodologies and educational levels.

Dynamic technologies supporting face-to-face collaboration and inquiry-exploratory pedagogies promote improved understanding and application of content [11, 16, 32, 39], skill development [11, 39], attitudes toward content and self-efficacy [32] and learning gains, particularly with low achieving students [5]. Dynamic technologies such as virtual simulations can provide authentic learning experiences similar to that of a physical laboratory component in physics classes. Virtual laboratories can help students deepen their understanding of concepts [39], reduce cognitive load, revisit certain parts, test and re-test ideas, and receive feedback [27]. Among the sampled papers emphasizing game-based pedagogy and tools, results indicated active collaborative partnerships formed during game play might be useful for encouraging learners to articulate their understanding of concepts and making their thinking visible $[16,32]$. Moreover, while games-based pedagogies allowed learners to explore, strategize, and solve problems primarily without the help of the teacher, game-based tools and other resources may enhance collaborative processes (e.g. a shared repertory tool or virtual product design tools) and support self-efficacy. Among these sampled papers, the results indicated face-to-face mediated collaboration had a positive effect on collaborative processes, and individual and group outcomes [11, 32, 39]. Furthermore, face-to-face collaboration in combination with knowledge scaffolds may be necessary for developing higher order thinking and content understanding [38].
Although these papers demonstrated that technologies could support constructivist-learning activities, there were some limitations. Sung and Hwang [32] suggested that if virtual tools were not properly scaffolded, they could interfere with how learners used the technology; therefore proper integration and support is needed in order for learners to receive maximum benefits from its use. Learners may also need some orientation to figure out best ways to use the tools to accomplish goals, especially in the wake of system constraints and limitations [11]. System constraints can limit what can actually be done in the environment and how people collaborate, which can deter or inspire problem solving. For instance, in Girvan et al. [11], interviews highlighted the challenges in creating artifacts in a virtual world. In particular such issues as dealing with the allocation of virtual building blocks led to abandoning ideas and impairing collaboration and problem solving processes.

\subsection{Cluster 3: Asynchronous discussion}

Cluster 3, the "Asynchronous Discussion" cluster, represents papers focused on asynchronous collaboration with an emphasis on discussion pedagogies that use asynchronous communication technologies such as Knowledge Forum (KF; [2], 24, 33 and online discussion boards $[6,7,19,20,26]$. KF is a technological platform where participants can engage in knowledge building, a process in which participants work together to advance the community's understanding [28]. Discussion boards and knowledge forum dominate the technologies here along with the concomitant use of general discussion pedagogy, knowledge building along with scaffolding, argumentation, and scripting pedagogies. Online discussion boards can vary in their uses, but in the sampled papers, participants used an online discussion board to improve their content knowledge $[6,7,19,20]$, reflect on face-to-face classroom activities [19], and develop arguments [20].

The results from these sampled papers indicate the use of asynchronous discussion in K-12 and in higher education produce positive effects. These include improvement in argumentation [20], discussion quality [23], knowledge-building skills [2], content knowledge $[6,7,23]$, and diverse questioning [33].

Additionally, Lee [19] found students who posted elaborate responses and initiated discussions tended to perceive the discussion forum beneficial to their learning process and had positive emotions about participating in the discussion. In many of these examples, the authors emphasize the benefits of asynchronous collaboration using asynchronous technological tools as a way to encourage participants 
Table 2. Cluster composition and descriptions

\begin{tabular}{|c|c|c|c|c|}
\hline & $\begin{array}{l}\text { Cluster 1: } \\
\text { Mixed } \\
\text { Asynchronous }\end{array}$ & $\begin{array}{l}\text { Cluster 2: } \\
\text { Mediated } \\
\text { Inquiry }\end{array}$ & $\begin{array}{l}\text { Cluster 3: } \\
\text { Asynchronous } \\
\text { Discussion }\end{array}$ & $\begin{array}{l}\text { Cluster 4: } \\
\text { Mixed } \\
\text { Synchronous }\end{array}$ \\
\hline \multicolumn{5}{|l|}{ Collaboration } \\
\hline Asynchronous & 41 & 1 & 30 & 0 \\
\hline Mediated & 13 & 118 & 0 & 0 \\
\hline Synchronous & 10 & 0 & 1 & 31 \\
\hline Various & 35 & 3 & 7 & 5 \\
\hline \multicolumn{5}{|l|}{ Pedagogy } \\
\hline Discussion & 26 & 3 & 15 & 1 \\
\hline Inquiry and Exploration & 18 & 72 & 0 & 4 \\
\hline Teacher directed & 18 & 0 & 2 & 1 \\
\hline Other & 11 & 15 & 3 & 11 \\
\hline Various & 26 & 32 & 18 & 19 \\
\hline \multicolumn{5}{|l|}{ Technology } \\
\hline Asynchronous communication & 0 & 2 & 31 & 0 \\
\hline Synchronous communication & 0 & 0 & 0 & 6 \\
\hline Dynamic representational tools & 0 & 42 & 0 & 9 \\
\hline Groups and communities & 0 & 3 & 3 & 7 \\
\hline Integrated Environment & 30 & 4 & 0 & 0 \\
\hline Other & 0 & 33 & 4 & 7 \\
\hline Sharing and co-construction & 35 & 21 & 0 & 0 \\
\hline Various & 34 & 17 & 0 & 7 \\
\hline Total papers in cluster & 99 & 122 & 38 & 36 \\
\hline
\end{tabular}


Table 3. Cluster composition disaggregated by pedagogy by superordinate category

\begin{tabular}{|l|r|r|r|r|}
\hline & \multicolumn{4}{|l}{ Cluster } \\
\hline Pedagogy Type & $\mathbf{1}$ & $\mathbf{2}$ & $\mathbf{3}$ & $\mathbf{4}$ \\
\hline Teacher-directed & & & & \\
\hline Traditional instruction & 0 & 1 & 0 & 1 \\
\hline Distance Learning & 18 & 0 & 6 & 4 \\
\hline MOOCS & 2 & 0 & 0 & 0 \\
\hline Blended Learning & 16 & 1 & 6 & 1 \\
\hline Case-based instruction & 5 & 9 & 0 & 2 \\
\hline Problem solving & 2 & 5 & 1 & 5 \\
\hline $\begin{array}{l}\text { Inquiry and } \\
\text { Exploration }\end{array}$ & & & & \\
\hline Game & 1 & 12 & 0 & 3 \\
\hline $\begin{array}{l}\text { Problem-/Project- } / \\
\text { Design-based }\end{array}$ & 12 & 18 & 1 & 1 \\
\hline Active/Hands-on & 11 & 36 & 3 & 2 \\
\hline Discovery & 1 & 7 & 0 & 1 \\
\hline Inquiry & 4 & 23 & 0 & 3 \\
\hline Discussion & & & & \\
\hline Discussion & 23 & 5 & 20 & 6 \\
\hline Knowledge Building & 14 & 10 & 7 & 3 \\
\hline Argumentation & 3 & 5 & 6 & 1 \\
\hline Scripts and roles & 6 & 3 & 4 & 3 \\
\hline Scaffolding & 9 & 21 & 12 & 21 \\
\hline Other & 9 & 10 & 6 & 6 \\
\hline & & & \\
\hline
\end{tabular}

to take more time to think critically, evaluate others' thoughts, and provide support and justification for their own messages $[2,6,19,20,23]$. In addition, Tan and Seah [33] noted how the use of these tools can help teachers identify and track students' ideas through the development of their questions and Romero et al. [26] were able to predict university students' final performance through their participation in an online discussion forum in a computer science course

Learners' perception of online discussions, of their learning, their motivation and willingness to stimulate discussions with new ideas and questions moderated their learning process. Meanwhile, the findings of Chen et al. [7] help us better understand the effects of e-authors' evaluation and knowledge content.
Table 4. Cluster composition disaggregated by technology by superordinate category

\begin{tabular}{|l|r|r|r|r|}
\hline & \multicolumn{4}{|l|}{ Cluster } \\
\hline Technology type & $\mathbf{1}$ & $\mathbf{2}$ & $\mathbf{3}$ & $\mathbf{4}$ \\
\hline Asynchronous & & & & \\
\hline Email & 3 & 0 & 0 & 1 \\
\hline Discussion Board & 9 & 1 & 22 & 2 \\
\hline Knowledge Forum & 4 & 2 & 8 & 1 \\
\hline Synchronous & & & & \\
\hline Chat & 3 & 0 & 0 & 6 \\
\hline Video Conference & 4 & 0 & 0 & 4 \\
\hline Sharing and Co-Construction & & & & \\
\hline Participatory technology & 25 & 5 & 0 & 1 \\
\hline Representational tools & 6 & 8 & 0 & 1 \\
\hline Shared Workspace & 8 & 2 & 0 & 1 \\
\hline Interactive White board & 1 & 1 & 0 & 1 \\
\hline Dynamic Tools & & & & \\
\hline Simulations & 3 & 31 & 0 & 4 \\
\hline Immersive Technology & 2 & 12 & 0 & 5 \\
\hline Game & 3 & 15 & 1 & 3 \\
\hline Groups and Communities & & & & \\
\hline Social Media & 2 & 1 & 1 & 2 \\
\hline Information Resources & 17 & 13 & 0 & 0 \\
\hline $\begin{array}{l}\text { Peer Assessment/feedback } \\
\text { system }\end{array}$ & 2 & 4 & 1 & 4 \\
\hline Integrated Environment & 32 & 7 & 1 & 4 \\
\hline Other & & & & \\
\hline Intelligent Systems & 6 & 12 & 1 & 5 \\
\hline Group awareness & 3 & 3 & 1 & 2 \\
\hline Mobile & 1 & 13 & 0 & 0 \\
\hline Table top & 2 & 8 & 0 & 0 \\
\hline Other hardware & 14 & 2 & 3 \\
\hline Other software & &
\end{tabular}

Specifically, positive social cues in messages during content disagreements can help students maintain online social relationships. This finding gives us insight in the importance of guiding students to evaluate others' ideas constructively.

In contrast, students who had a poor perception of online discussions were less inclined to make substantive postings (i.e., creating new topic for discussion, initiating messages, or supporting their 
messages with references), only doing the minimal to satisfy course requirements $[6,19]$.

\subsection{Cluster 4: Mixed synchronous}

Cluster 4, the "Mixed Synchronous" cluster, represents papers emphasizing synchronous collaboration, with various pedagogies that use dynamic or group and community technological tools. Dominant pedagogies in this cluster tended to include considerable scaffolding as shown in Table 3, along with problem-solving activities and discussion. There was considerable variability among technology is this cluster. Of the papers sampled in this cluster, there did not appear to be differences across K12 and higher education. These papers used a variety of pedagogies guided by social constructivist principles such as inquiry-based instruction [30], case based instruction [8], scaffolding [10, 21, 29, 36, 37], and computer simulation [4].

The use of these tools while engaged in synchronous CSCL driven by social constructivist pedagogies encouraged effective active participation whether that be through chat $[10,29,30,37]$, tweeting [21], shared word processing and audio connection [8], adapted collaborative learning support (ACLS) [37], a semi-computerized inference tutoring tool [8], scripts [4] or a "game like" peer tutoring system [36].

Descriptive results indicate, from instructors' perspectives, communicating with these tools seemed especially beneficial to increase participation among students who might have otherwise been absent and/or shy or quiet during face-to-face class time [21, 29]. Among researchers examining synchronous collaboration among primary mathematics students, results indicated that students thoughtfully and successfully engaged in problem solving while participating in a virtual environment [4] and online peer tutoring that improved tutored students' mathematical reasoning skills in addition to personal views about mathematics learning [36]. Additionally, students enrolled in a blended higher-education engineering course viewed chat as one of the best tools in the Second Life (SL) platform to support learning [29]. Eight-five percent of students surveyed from two higher-education computer science courses that integrated tweeting to increase class discussion found the use of tweeting in their class stimulated their desire to learn more about the course content and $93 \%$ of surveyed students believed their university should offer more courses with tweeting activities [21]. Aside from active participation and positive perceptions of these CSCL tools, the results from these sampled papers found other ways "Mixed
Synchronous" CSCL to be effective for learners. Three of these sampled papers quantitatively examined the effectiveness of particular tools with synchronous dyads in controlled settings [8, 20, 37]. An additional sampled paper used mixed methods to examined how gender pairings affected student's' knowledge elaboration processes and learning achievement [10]. In all four of these sampled papers, the authors found their CSCL tools to be particularly beneficial to student learning.

In many ways "Mixed Synchronous" CSCL is particularly effective as it encourages active participation, yet this very participation also has potential negative consequences. Although, the majority of students enrolled in the higher-education blended-learning engineering course reported the SL platform 'better' for motivation, they also reported it 'worse' for concentration [29]. Additionally, although higher-education computer-science students overwhelmingly tweeted constructive comments that encouraged class discussion, there were also examples of students tweeting unrelated comments [21]. Other potential drawbacks to "Mixed Synchronous" CSCL included the additional time communicating via chat took as compared to face-toface interactions [30] and the finding that mixedgender pairing may negatively affect secondary education female achievement in physics problem solving [10]. For example, female students placed in a mixed gender dyad performed relatively worse on a posttest than females in single gender dyads. Students in mixed gender dyads showed more instances of divergent knowledge elaboration, suggesting a gap in communication, had a negative impact on learning performance for the female student [10].

\section{Conclusions and Implications}

CSCL research lies at the intersection of digital and social media and pedagogy. This cluster analysis provided a way to look more closely at CSCL research studies across several dimensions (e.g. collaboration, pedagogy, technologies, levels, domains). It allowed us to identify common moderators that affect the collaborative meaning making process and learning outcomes in the digital technologies and social media that are part and parcel of CSCL (e.g., [2, 4, 11, 15, 16, 21, 25].

CSCL tools and pedagogies typically improve collaborative learning processes along with achieving other learning and motivational goals; nonetheless, several cases highlight when CSCL is not effective. For instance, some papers showed that in traditional online forums, engagement can often times be 
sporadic, and contributions can be short, ill-formed, or created irrespective of previous contributions, all which tend to diminish the positive affordances of discussion forums (i.e. that online forums should offer space for reflection and critical thinking); [2, 7, 19]. In Cluster 4, tweeting caused some off-task activity and minor distractions among students and some students rather preferred face-to-face communication than communicating through chat. Finally, there may be some undesired gender effects such as communication gaps in knowledge elaboration. Instead of students working together, taking turns, and negotiating meaning to build on prior knowledge, students in mixed gender groups might take on a pattern of communication that results in individuals taking separate knowledge elaboration paths that can become increasingly divergent. As a result, one student may take on a dominant role while the other lags behind, which may impair learning performance, particularly for females in mixed groups [10]. Thus, designers and practitioners need to be aware of these undesired possibilities and consider how pedagogical designs can maximize advantages of the digital technologies and social media used in CSCL.

The current synthesis shed lights on the complexities involved in using technologies to support learning in the dynamic social environment of teaching. For example, social media technologies are actively used to support learning in CSCL. Our synthesis identified both positive as well as negative outcomes associated with them. Although CSCL can motivate students by mixing informal social relations into learning, but it can also distract students from learning as we have shown in the Cluster 4 synthesis. Social goals are also likely dominate over learning goals, yet helping learners to stay focused on their learning agenda while not missing out on the fun is critical for this technology to be successful. In addition, in order for the social media exchanges to be meaningful, they need to be integrated into a coherent whole. Synthesis outcomes from Cluster 1 suggest that maintaining such coherence is difficult even in formal asynchronous environments. The challenge is bigger in social media as content and discussion topics are updated and change more rapidly without clear overarching plan. Helping students to find coherence from multiple threads of postings and networks is likely to be critical for social media to become more a more productive learning tool.

This synthesis suggests that these learning environments can effectively use constructivist pedagogies, which are well supported with diverse set of tools such as simulations or co-construction tools, particularly when it comes to face-to-face or synchronous collaboration. CSCL can be effective in knowledge building with discussion pedagogies using asynchronous technologies, but they require the presence of moderating factors such as explicit guidance, perceived degree of social presence, and intrinsic motivation. Yet, there is still a need for more sophisticated pedagogies that integrate formal and informal learning and also take social relations and digital media more seriously.

We have some preliminary understanding of how different combinations of pedagogy, technology and collaboration may moderate the effectiveness of CSCL in STEM learning, however, we still need to better understand under what circumstances is CSCL most effective and for whom. Although it would be nice to be able to provide definitive answers to questions about what is effective, there is a considerable variability in how CSCL technologies are used and which defies any simple answer. Here lies complex questions that this meta-synthesis project is trying to address and the current study is the beginning to do that to this end. Further research may contribute to our understanding of technological trends and the potential affordances of these technologies. One outcome of this research is a model of the affordances that CSCL environments need to support in various combinations [12]. These seven affordances include:

- Providing tools for communication

- Collaborative tasks

- Structuring the collaborative learning process,

- Facilitating the sharing and creation of resources, supporting knowledge

- Co-construction and intersubjectivity,

- Helping with monitoring and regulation

- Forming groups and communities.

Our ongoing effort is examining how appropriate combinations of these affordances can be realized through technology and pedagogy (and indeed what those appropriate combinations are). This is an important step in understanding how specific digital technologies and social media can be productively used to support collaborative meaning makingwhen used in particular ways and for particular kinds of outcomes.

\section{References}

[1] Bair, C. R. (1999). Meta-synthesis. Paper presented at the Association for the Study of Higher Education, San Antonio, TX. 
[2] Bielaczyc, K. \& Ow, J. (2013). Multi-player epistemic games: Guiding the enactment of classroom knowledgebuilding communities. International Journal of ComputerSupported Collaborative Learning, 9, 33-62.

[3] Blooma, M. J., Kurian, J. C., Chua, A. Y. K., Goh, D. H. L., \& Lien, N. H. (2013). Social question answering: Analyzing knowledge, cognitive processes and social dimensions of micro-collaborations. Computers \& Education, 69, 109-120.

[4] Bouta, H., Retalis, S., \& Paraskeva, F. (2012). Utilising a collaborative macro-script to enhance student engagement: A mixed method study in a 3D virtual environment. Computers \& Education, 58, 501-517.

[5] Cai, S., Wang, X., \& Chiang, F. K. (2014). A case study of Augmented Reality simulation system application in a chemistry course. Computers in Human Behavior, 37, 3140

[6] Chen, G., Chiu, M. M., and Wang, Z. (2012a). Social metacognition and the creation of correct, new ideas: A statistical discourse analysis of online mathematics discussions. Computers in Human Behavior, 28, 868 - 880.

[7] Chen, G., Chiu, M. M., \& Wang, Z. (2012b). Predicting social cues during online discussions: Effects of evaluations and knowledge content. Computers in Human Behavior, 28(4), 1497-1509.

[8] Deiglmayr, A., \& Spada, H. (2011). Training for fostering knowledge co-construction from collaborative inference-drawing. Learning and Instruction, 21(3), 441451.

[9] Dillenbourg, P., Järvelä, S., \& Fischer, F. (2009). The evolution of research on computer-supported collaborative learning. In $\mathrm{N}$. Balacheff, $\mathrm{S}$. Ludvigsen, $\mathrm{T}$. Jong, $\mathrm{T}$. Lazonder, A \& S. Barnes (Eds.), Technology-enhanced Learning (3-19). Netherlands: Springer.

[10] Ding, N., Bosker, R. J., \& Harskamp, E. G. (2011). Exploring gender and gender pairing in the knowledge elaboration processes of students using computer-supported collaborative learning. Computers \& Education, 56(2), 325-336.

[11] Girvan, C., Tangney, B., \& Savage, T. (2013). SLurtles: supporting constructionist learning in Second Life. Computers \& Education, 61, 115-132.

[12] Joubert, M., \& Wishart, J. (2012). Participatory practices: Lessons learnt from two initiatives using online digital technologies to build knowledge. Computers \& Education, 59(1), 110-119.

[13] Jeong, H. Hmelo-Silver, C. E., Jo, K. \& Shin, M. (2016). CSCL in STEM education: Preliminary findings from a meta-analysis. In Proceedings $49^{\text {th }}$ Annual Hawaii International Conference on System Sciences. (pp. 11-20). Piscataway, NJ. IEEE Computer Society Press.

[14] Jeong, H. \& Hmelo-Silver, C. E. (2016). Seven affordances of CSCL Technology: How can technology support collaborative learning. Educational Psychologist. $51,247-265$.

[15] Jeong, H., Hmelo-Silver, C. E., Yu, Y. (2014). An examination of CSCL methodological practices and the influence of theoretical frameworks 2005-2009. iJCSCL, 9, 305-344.

[16] Ke, F. (2013). Computer-game-based tutoring of mathematics. Computers \& Education, 60(1), 448-457.

[17] Lan, Y. F., Lin, P. C., \& Hung, C. L. (2012a). An approach to encouraging and evaluating learner's knowledge contribution in Web-based collaborative learning. Journal of Educational Computing Research, 47, $107-135$

[18] Lan, Y. F., Tsai, P. W., Yang, S. H., \& Hung, C. L. (2012b). Comparing the social knowledge construction behavioral patterns of problem-based online asynchronous discussion in e/m-learning environments. Computers \& Education, 59, 1122-1135.

[19] Lee, S. W. Y. (2013). Investigating students' learning approaches, perceptions of online discussions, and students' online and academic performance. Computers \& Education, 68, 345-352.

[20] Lin, H. S., Hong, Z. R., \& Lawrenz, F. (2012). Promoting and scaffolding argumentation through reflective asynchronous discussions. Computers \& Education, 59(2), 378-384.

[21] Menkhoff, T., Chay, Y. W., Bengtsson, M. L., Woodard, C. J., \& Gan, B. (2014). Incorporating microblogging ("tweeting") in higher education: Lessons learnt in a knowledge management course. Computers in Human Behavior. 51, 1295-1302

[22] Miyake, N. (2007). Comuter supported collaborative learning. In R. Andrews \& C. Haythornwaite (Eds.), Sage handbook of E-learning research (pp. 248-266). London UK: Sage.

[23] Nason, R. Chalmers, C. \& Yeh, A. (2012). Facilitating growth in prospective teachers' knowledge: teaching geometry in primary schools. Journal of Mathematics Teacher Education, 15, 227-249.

[24] Papadopoulos, P. M., Demetriadis, S. N., \& Weinberger, A. (2013). 'Make it explicit!': Improving collaboration through increase of script coercion. Journal of Computer Assisted Learning, 29), 383-398.

[25] Pifarré, M \& Staarman, J. K. (2011). Wiki-supported collaborative learning in primary education: How a dialogic space is created for thinking together. Computer-Supported Collaborative Learning, 6, 187-205.

[26] Romero, C., López, M. I., Luna, J. M., \& Ventura, S. (2013). Predicting students' final performance from participation in on-line discussion forums. Computers \& Education, 68, 458-472.

[27] Santos-Martin, D., Alonso-Martinez, J., Carrasco, J. E. G., \& Arnaltes, S. (2012). Problem-based learning in wind 
energy using virtual and real setups. Education, IEEE Transactions on, 55, 126-134.

[28] Scardamalia, M., \& Bereiter, C. (2014). Knowledge building and knowledge creation: Theory, pedagogy, and technology. In R. K. Sawyer (Ed.), Cambridge handbook of the learning sciences (Second ed., pp. 397-417). New York: Cambridge University Press.

[29] Sierra, L. M. B., Gutiérrez, R. S., \& Garzón-Castro, C. L. (2012). Second Life as a support element for learning electronic related subjects: A real case. Computers \& Education, 58, 291-302.

[30] Sins, P. H., Savelsbergh, E. R., van Joolingen, W. R., \& van Hout-Wolters, B. H. (2011). Effects of face-to-face versus chat communication on performance in a collaborative inquiry modeling task. Computers \& Education, 56, 379-387.

[31] Stahl, G., Koschmann, T., \& Suthers, D. D. (2014). Computer-supported collaborative learning. In R. K. Sawyer (Ed.), Cambridge handbook of the learning sciences (2nd ed., pp. pp. 479-500). NY: Cambridge University Press.

[32] Sung, H. Y., \& Hwang, G. J. (2013). A collaborative game-based learning approach to improving students' learning performance in science courses. Computers \& Education, 63, 43-51.

[33] Tan, S. C., \& Seah, L. H. (2011). Exploring relationship between students' questioning behaviors and inquiry tasks in an online forum through analysis of ideational function of questions. Computers \& Education, 57(2), 1675-1685.
[34] Thoms, B., \& Eryilmaz, E. (2014). How media choice affects learner interactions in distance learning classes. Computers \& Education, 75, 112-126.

[35] Timmis, S. (2014). The dialectical potential of Cultural Historical Activity Theory for researching sustainable CSCL practices. International Journal of Computer-Supported Collaborative Learning, 9(1), 7-32.

[36] Tsuei, M. (2012). Using synchronous peer tutoring system to promote elementary students' learning in mathematics. Computers \& Education,58(4), 1171-1182.

[37] Walker, E., Rummel, N., \& Koedinger, K. R. (2014). Adaptive intelligent support to improve peer tutoring in algebra. International Journal of Artificial Intelligence in Education, 24(1), 33-61.

[38] Yoon, S. A., Elinich, K., Wang, J., Steinmeier, C., \& Tucker, S. (2012). Using augmented reality and knowledge-building scaffolds to improve learning in a science museum. International Journal of ComputerSupported Collaborative Learning, 7(4), 519-541.

[39] Zacharia, Z. C., \& Olympiou, G. (2011). Physical versus virtual manipulative experimentation in physics learning. Learning and Instruction, 21(3), 317-331.

\section{Acknowledgements}

This work is funded by the National Science Foundation Grant \# DRL-1439227. Conclusions or recommendations expressed in this material are those of the authors and do not necessarily reflect the views of the National Science Foundation. We thank Jessica McKeown and Alejandro Andrade for their able assistance with data analysis. 